\title{
NORMAS, VERDAD Y LÓGICA FORMAL
}

\author{
Manuel Manson \\ Universidad de Buenos Aires (Argentina)
}

\section{A. Kalinowski y la tesis del derecho positivo verdadero}

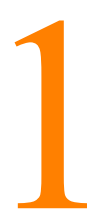

En El problema de la verdad en la moral y en el derecho (Eudeba, Buenos Aires, 1979), Kalinowski presenta como central una cuestión que formula diciendo: «¿existen una moral y un derecho verdaderos y -en caso afirmativo- cómo se verifican los juicios que los integran?» (p. XIV).

El problema reviste, a juicio del autor, especial significación tratándose de «las normas sancionadas por el hombre en virtud del poder legislativo autónomo que le ha sido delegado por la ley natural» (pp. 151-152).

2. Para Kalinowski, las normas jurídicas serían enunciativas: serían susceptibles de ser calificadas de verdaderas o falsas. En su opinión, tendrían este carácter las leyes estatales.

«La ley natural -escribe Kalinowski- obliga con carácter general a hacer lo que es propicio al bien común, a la vida social y a evitar lo que les perjudica. Contiene, entonces, en forma implícita para las épocas y países en los que la circulación no reglamentada sería socialmente peligrosa, la norma alternativa: "Es necesario circular por la derecha o por la izquierda". Pero al mismo tiempo no contiene en esta cuestión ninguna norma categórica. Esto hace que las normas del tránsito en vigor en Francia y en Inglaterra se fundamenten ambas en la ley natural sin ser simples conclusiones de ella. En realidad, el legislador francés ha observado que de acuerdo con la ley natural se debía circular en Francia por la derecha o por la izquierda y que no había obligación categórica de circular por la izquierda, comprobación de la que concluyó según la regla de razonamiento fundada sobre el modus tollendo ponens que en Francia se debería circular por la derecha, mientras que en su caso el legislador inglés observó que con arreglo a la ley natural en Inglaterra se debía circular por la izquierda o por la derecha y que no había obligación categórica de circular por la derecha, comprobación tan exacta como la del legislador francés y que le permitió concluir con arreglo al mismo modus tollendo ponens que en Inglaterra se debería circular por la 
izquierda. Si nuestro análisis es exacto los códigos de tránsito en las rutas inglesas y francesas son igualmente verdaderos porque son igualmente conformes con la ley natural (el primero con un término y el segundo con el otro término de la norma alternativa en cuestión, implicada por la ley natural, evocada más arriba)» (p. 153).

3. Pero el modus tollendo ponens -«Si p o q y no-q, entonces $\mathrm{p} »$, expuesto por el propio Kalinowski (p. 153, n. 5)- no sería aplicable, ya que la norma «Es necesario circular por la derecha o por la izquierda» no tiene la forma «p o q». En dicha norma «Es necesario» («Se debe», «Debe ser») es un operador cuyo ámbito es la expresión «circular por la derecha o (circular) por la izquierda».

La forma de la norma es, más bien, «Debe ser (p o q)».

4. De la norma ideada por Kalinowski y de enunciados de «comprobación» no se infieren las normas del tránsito establecidas por los legisladores francés e inglés.

Si el legislador francés comprobó que «no había obligación categórica de circular por la izquierda», pudo también comprobar que «no había obligación categórica de circular por la derecha». Por otra parte, las oraciones llamadas a expresar las respectivas constataciones no constituyen la negación de una norma imperativa (no tienen la fuerza de un permiso).

\section{B. Klug y la distinción entre normas y enunciados jurídicos}

1. Klug estima que «tiene pleno sentido preguntar por la verdad de las normas» (Lógica jurídica, trad. de la 4a. ed. en alemán, Temis, Bogotá, 1990, p. 259).

«La legitimidad de la cuestión sobre la verdad de las normas, que aquí defendemos -escribe Klug- se fundamenta en el hecho de que aceptamos el concepto de proposición verdadera, tal como fue definido metalingüísticamente ya por Tarski para los lenguajes formalizados. Según ese concepto, la proposición 'nadie puede ser obligado contra su conciencia a prestar servicio militar con armas' será entonces y sólo entonces verdadera cuando nadie pueda ser obligado contra su conciencia a prestar servicio militar con armas» (p. 260).

2. A juicio de Klug, «tanto las normas generales como también las individuales se formulan por el respectivo órgano emisor de normas -legislador o juez- como enunciados que dicen que es verdadero o falso, que algo está mandado, prohibido o permitido» (pp. 258-259).

«Si el condenado era en realidad inocente -dice Klug- esto quiere decir que el tribunal había partido de premisas de hecho falsas... Sólo cuando se establece la falsedad de estas premisas por una nueva sentencia en un proceso de revisión, cuando se eliminan los axiomas en función de los cuales 
resulta verdadero el hecho que se había admitido, se suprimirá entonces la norma individual establecida en la primera sentencia. Solo entonces será falso que el acusado tenga la obligación de cumplir una pena privativa de libertad... Pero, entre tanto, la primera norma individual sigue siendo verdadera» (p. 259).

3. Klug no distingue convenientemente entre normas y enunciados deónticos.

En un enunciado, la expresión «puede que sea obligado» tiene en su totalidad significado cognitivo y se emplea descriptivamente, en una norma, la expresión sería intercambiable con «iPermítese que sea obligado...!», al tener «puede» solamente significado directivo. Cabe decir, sin duda: «La oración "nadie puede ser obligado contra su conciencia a prestar servicio militar con armas" es verdadera si y sólo si nadie puede ser obligado contra su conciencia a prestar servicio militar con armas». Pero una formulación semejante no convierte una norma en un enunciado. Al atribuir verdad o falsedad a una oración se entiende que ella es un enunciado.

La norma que prohíba, por ejemplo, que alguien sea obligado contra su conciencia a prestar servicio militar con armas se distingue del enunciado del jurista que expresa que está prohibido que alguien sea obligado contra su conciencia a prestar servicio militar con armas. Las normas no son «enunciados que dicen que es verdadero o falso, que algo está mandado, prohibido o permitido». Son disposiciones que mandan, prohíben o permiten. Por otra parte, ni ser axioma es lo mismo que ser verdadero, ni el que una norma esté vigente hace que sea verdadera.

\section{Castañeda y los sistemas normativos}

1. Héctor-Neri Castañeda, a su vez, luego de afirmar que «una norma es un principio de acción», que los códigos morales de las distintas comunidades y los sistemas legales de las naciones se cuentan entre «los sistemas normativos más importantes», y que «los sistemas normativos son (al menos en parte) sistemas de normas o juicios deónticos», sostiene: «las normas características de un sistema normativo $\mathrm{N}$ son de la siguiente forma canónica:

F) Es requerido de $\mathrm{X}$ por $\mathrm{N}$ [o X debe, $\mathrm{N}$-mente], hacer $\mathrm{A}$, en que la frase adverbial [por $\mathrm{N}$ o «N-mente»] señala el tipo de requerimiento determinado por el sistema N" (Pensar y hacer. Los fundamentos filosóficos de las instituciones, UNAM, México, 1993, pp. 15, 16 y 17).

Castañeda confunde los preceptos del sistema $\mathrm{N}$ con enunciados (metalingüísticos) relativos a N. En rigor, son precisamente éstos últimos los que tienen la forma canónica «Es requerido de $\mathrm{X}$ por $\mathrm{N}$, hacer $\mathrm{A} »$. 
2. En su confusión, Castañeda dice que «un enunciado deóntico, exactamente igual que un mandato, puede no ser cumplido o hasta ser desobedecido», pese a expresar, asimismo: «se habla apropiadamente de los noemas deónticos como verdaderos o falsos. Por ejemplo: es verdad que en los Estados Unidos uno debe manejar del lado derecho del camino; es verdad que los residentes de Detroit tienen que pagar a la Ciudad de Detroit un impuesto sobre sus ingresos; es verdad que en la Universidad Estatal de Wayne un profesor ayudante tiene derecho a solicitar el Premio de Reconocimiento del Fondo Estatal de Wayne... Indudablemente, hay procedimientos de verificación para los juicios deónticos. Algunos de ellos permiten una verificación completa. Por ejemplo, cuando Secundus le promete a Privatus enseñarle inglés, Secundus sabe concluyentemente que tiene el deber de enseñar inglés a Privatus. Algunas obligaciones legales pueden precisarse completamente consultando los libros de derecho» (op. cit., pp. 213 y 215).

3. Pero, el que, por ejemplo, sea verdad que en los Estados Unidos uno debe manejar del lado derecho del camino -de suerte que sea verdadero el enunciado «En los Estados Unidos uno debe manejar del lado derecho del camino»- o el que algunas obligaciones legales «pueden precisarse completamente consultando los libros de derecho», no constituye antecedentes que justifiquen el planteamiento de Castañeda.

Hay que distinguir entre los enunciados sobre el sistema jurídico de los Estados Unidos -como aquél según el cual «en los Estados Unidos uno debe manejar del lado derecho del camino»- y las normas de dicho sistema. Si éstas prescribiesen que se maneje del lado izquierdo del camino, entonces un enunciado como el ya expuesto sería falso. Como Castañeda manifiesta, una promulgación «crea nuevas obligaciones, deberes o similares, o crea nuevos derechos, o permisos, o libertades para actuar» (op. cit., p. 219).

Secundus «sabe concluyentemente que tiene el deber de enseñar inglés a Privatus» porque sabe que él mismo ha constituido ese deber, al prometerle a Privatus enseñarle inglés. Sin la promesa, ese deber no se habría constituido. Lo que está sometido a procedimientos de verificación es el enunciado relativo a la promesa y al deber creado por ella, mas no la promesa misma. El enunciado es «declarativo»; la promesa, «creadora».

\section{Schreiber y la «tesis de descripción»}

1. En Lógica del derecho (Sur, Buenos Aires, 1967), Schreiber formula una «tesis de descripción».

«La tesis de descripción -escribe Schreiber- reza: Las proposiciones normativas pueden ser reducidas a proposiciones indicativas... El contenido de la tesis de descripción afirma que las proposiciones normativas del lenguaje jurídico pueden ser traducidas a proposiciones indicativas... To- 
memos como ejemplo una proposición del derecho civil: "Es debido que Maier pague a Huber 20 DM". La validez de esta proposición significa que si Maier no paga a Huber los 20 DM, este último puede recurrir a la vía judicial... Pero no podemos limitar las consecuencias de una proposición normativa individual a la actividad de los órganos de la administración de justicia. Esta proposición provoca también consecuencias económicas» (pp. 100-101).

Schreiber, en verdad, añade: «Tendremos que tener en cuenta no sólo los efectos económicos sino también los efectos sociales en general de esta proposición, a fin de poder describir su significado» (p. 101). Y prosigue: «Habrá también que considerar, como grupo importante, los efectos psíquicos de la proposición jurídica en los que intervienen en el proceso» (p. 101).

2. La «tesis de descripción» de Schreiber acoge tres planteamientos criticables: (a) «de la validez de la norma jurídica resulta su eficacia» y «de la eficacia resulta su validez» (p. 105); (b) «la validez de las normas jurídicas tiene el mismo significado que su eficacia» (p. 105); y (c ) el significado de una norma jurídica es el significado de las oraciones indicativas relativas a su eficacia (a las cuales «puede ser traducida»).

Según la «tesis de descripción», como reconoce Schreiber, «las oraciones del lenguaje jurídico son sometidas a los mismos criterios de verdad y falsedad del lenguaje descriptivo» («Logica deontica e teoria della validità», en G. di Bernardo (ed.), Logica deontica e semantica, Il Mulino, Bolonia, 1977, p. 323).

\section{E. Neumann y la concepción tarskiana de la verdad}

1. Neumann, en su trabajo «Lógica jurídica» (en A. Kaufmann, W. Hassemer (eds.), El pensamiento jurídico contemporáneo, Debate, Madrid, 1992, pp. 239-260), malinterpreta la concepción semántica de la verdad de Tarski.

«A diferencia de la teoría tradicional de la correspondencia, Tarski define la "verdad" -afirma Neumann- no como la concordancia entre la oración expresada y el estado de cosas real, sino como la relación entre proposiciones de distintos niveles, esto es, como la relación entre una proposición lingüística referida al objeto y una proposición metalingüística: "El enunciado "la nieve es blanca" es verdadero si y sólo si la nieve es blanca». La cuestión de lo que signifique realmente que la nieve es blanca puede quedar abierta sin respuesta, puesto que no se presupone la existencia del estado de cosas real aludido por la proposición lingüística que se refiere al objeto» (pp. 249-250).

2. Pero la concepción semántica de la verdad de Tarski no es sino «una forma modernizada» de la concepción clásica, según el mismo Tarski ma- 
nifiesta en su estudio «La concepción semántica de la verdad y los fundamentos de la semántica» (en M. Bunge (comp.), Antología semántica, Nueva Visión, Buenos Aires, 1960, p. 134).

La verdad, como atributo de oraciones, las sitúa en correspondencia con la realidad. Si la nieve no es blanca, no es verdadero el enunciado «la nieve es blanca»; en cambio, si este enunciado es verdadero, la nieve es blanca.

3. La concepción de Tarski no habilita para atribuir el carácter de enunciado, o sea, de expresión verdadera o falsa, a una oración cualquiera.

Si la frase «la nieve es blanca» no atribuyese blancura a la nieve ni predicase nada, no tendría sentido decir: «la nieve es blanca» es verdadera.

4. Neumann se equivoca al creer -junto con Ehrgen I'dig, a quien cita- que la cuestión sobre la procedencia de aplicar la lógica a las normas jurídicas se resuelve afirmativamente mediante el simple expediente de hablar de «verdad de las normas».

«Si no se ha de renunciar a la deducibilidad lógico-formal en el ámbito de las normas -escribe Neumann- entonces o bien habrá de entenderse de distinta manera la relación deductiva o bien habrá que revisar la negación del valor de verdad de las normas» (p. 249).

«La segunda solución -expresa Neumann- es la que, apoyándose en el concepto "semántico" de verdad desarrollado por Tarski, ha sido defendida con especial insistencia por Ehrgen I'dig» (p. 250). «La concepción de I'dig -asevera Neumann- parece viable y libre de contradicciones» (p. 250).

5. Según Neumann, se puede decir: «"Es obligatorio informar a las autoridades de la existencia de un delito inminente" es verdadero siempre que sea obligatorio informar a las autoridades de la existencia de un delito inminente» (p. 250). «La cuestión acerca de cuándo sucede tal cosa añade Neumann puede permanecer abierta, sin respuesta» (p. 250).

Neumann olvida, al parecer, que normas y enunciados deónticos suelen revestir igual terminología, pero con diversos significados.

Sólo se justifica atribuirle verdad a la oración mencionada por Neumann al ser propiamente un enunciado, o sea, al tener en ella la expresión «es obligatorio» un sentido cognitivo. $\mathrm{Si}$, en cambio, «es obligatorio» tiene sentido directivo, la oración no es un enunciado.

Cabe tener presente que, en otro de sus trabajos, el propio Neumann escribe: «La teoría de la correspondencia tiene que negar la capacidad de verdad de las normas, ya que éstas no establecen hecho alguno con el cual puedan concordar» («La teoría de la ciencia jurídica», en A. Kaufmann, W. Hassemer (eds.), El pensamiento jurídico contemporáneo, cit., p. 363). 


\section{F. MacCormick y los argumentos normativos}

1. Refiriéndose a argumentos con reglas jurídicas, MacCormick dice: «Si las premisas son verdaderas, necesariamente entonces la conclusión, concebida como proposición, es verdadera» (Legal Reasoning and Legal Theory, Clarendon Press, Oxford, 1978, p. 34).

El mismo autor afirma, asimismo, que las «proposiciones de derecho» «pueden, en verdad, ser verdaderas o falsas, en relación con un sistema jurídico determinado en un tiempo dado» (p. 271).

Sin duda, si se conciben como enunciados sobre normas jurídicas -«enunciados normativos»- las «proposiciones de derecho» serían verdaderas o falsas. Pero MacCormick a las reglas jurídicas mismas las considera «proposiciones de derecho» (pp. 29 y ss.).

2. En el capítulo final de Legal Reasoning and Legal Theory, MacCormick escribe: «podemos tener sistemas jurídicos racionalmente estructurados... El que podamos tenerlos me permite responder una posible objeción a la tesis presentada en el capítulo II, de que es posible el argumento deductivo en el derecho. En ese capítulo cometí lo que algunos querrían considerar como el obvio error de postular que puede haber enunciados "verdaderos" de las normas jurídicas que figuran en tales deducciones» (p. 271).

A juicio de MacCormick, la objeción estaría «bien fundada» si cuestionase la tesis de que hay «enunciados normativos verdaderos "absolutamente"» (p. 271). Según él, «dada la posibilidad de un conjunto coherente y consistente de reglas y principios, identificados directa o indirectamente con respecto a una "regla de reconocimiento", no tenemos problema en adscribir verdad relativa a las proposiciones de derecho» (p. 271).

El mismo MacCormick, para ilustrar su planteamiento, comienza expresando: «Si es verdad, como proposición del derecho escocés vigente, que toda persona que conduzca un automóvil por una autopista a más de 70 millas por hora comete una falta...» (p. 271).

3. MacCormick confunde normas con enunciados sobre normas y considera que éstas también son susceptibles de ser verdaderas o falsas.

MacCormick habla de «la cuestión fundamental del valor veritativo y naturaleza proposicional de las "proposiciones de derecho", que trato como premisas mayores de mis así llamados silogismos» («The nature of legal reasoning: a brief reply to Dr Wilson», Legal Studies, 2 (3), 1982, pp. 286-290). Según él, sus «proposiciones de derecho» son «directa o indirectamente» normativas; pero asevera que tal carácter «no es obstáculo para tratarlas como genuinamente proposicionales y susceptibles de poseer valor veritativo» (p. 289). 
A juicio de MacCormick, «aunque en su sentido más restringido a la lógica le interesa la validez más que la verdad en la argumentación, ella requiere el concepto de "valor veritativo" y presupone algunos criterios de verdad» (p. 290).

4. MacCormick tiene razón al afirmar que cuando «el Parlamento aprobó la sección 14 de la Ley de Venta de Mercaderías de 1893», el acto legislativo «no fue verdadero ni falso» («The nature of legal reasoning», cit., pp. 289-290). Pero no tiene toda la razón cuando añade, refiriéndose a ese acto legislativo y a otro de la judicatura: «Siendo válidos como actos jurídicos, establecieron reglas para los sistemas de derecho del Reino Unido. Y, dentro del universo del discurso legal, un enunciado que exprese correctamente los términos de una regla de derecho válida es un enunciado de derecho verdadero, que tiene como contenido una proposición de derecho verdadera» (op. cit., p. 290).

Sin duda, el acto legislativo establece reglas válidas al ser válido. Pero ellas no se convierten en «proposiciones verdaderas» sólo por ser de nuevo «correctamente expresadas». La autoridad judicial que expresa nuevamente los términos de una ley válida y la utiliza, por ejemplo, como una premisa de su argumentación, no por eso convierte a la ley en una «proposición de derecho verdadera».

\section{G. Cossio y la verificación de las normas jurídicas}

1. Según expresa Carlos Cossio, su doctrina presenta «la relación entre norma y conducta, como siendo la relación gnoseológica entre concepto y objeto», de manera que «ha de esperarse una confirmación o una decepción intuitivas para hablar de la verdad jurídica como juristas» («Teoría egológica y teoría pura», Revista de la Escuela Nacional de jurisprudencia, México, 45, 1950, pp. 121-174).

La norma, según Cossio, sería «verdadera» si «efectivamente el comportamiento concuerda con lo por ella mentado» («Las posibilidades de la lógica jurídica según la lógica de Husserl», Revista de la Facultad de Derecho y Ciencias Sociales, Buenos Aires, 23, 1951, pp. 201-241).

2. Desarrollando su doctrina, Cossio escribe: «La Teoría egológica ha denominado endonorma al primer miembro y perinorma al segundo. La prestación es lo que debe ser según la endonorma, pero según la perinorma es la sanción lo que debe ser. La norma completa resulta, por lo tanto, un juicio lógicamente disyuntivo. Como en toda disyunción proposicional, la verificación intuitiva de lo mentado sólo puede ocurrir respecto de uno u otro miembro de la alternativa... Aunque la conformidad de la conducta con la norma jurídica sólo puede ser con uno u otro miembro de la norma completa, para poder pensar jurídicamente el dato no bastan la endonorma o la 
perinorma por aparte... la simple verificación endonormativa ya positiviza a la norma completa; y otro tanto ocurre con la simple verificación perinormativa» (Teoría de la verdad jurídica, Losada, Buenos Aires, 1954, pp. 134-135).

3. En conformidad al criterio de Cossio sobre los juicios disyuntivos -según el cual «la verificación intuitiva de lo mentado sólo puede ocurrir respecto de uno u otro miembro»su norma «completa» sería «falsa» si se cumplen sus dos componentes.

En rigor, en una formulación adecuada de la «norma completa», "debe ser que el arrendatario pague el alquiler» («endonorma») y «sí el arrendatario no paga el alquiler, entonces debe ser desahuciado» («perinorma») se conectan conjuntivamente, siendo posible que ambas se cumplan -lo que ocurriría si el arrendatario paga el alquiler. También es posible, por cierto, que las dos normas sean incumplidas, lo que sucedería si el arrendatario no paga y no es desahuciado.

4. Por otra parte, para la tesis sobre la «verificación intuitiva de lo mentado», la expresión «debe ser» no desempeña ninguna función.

La «verificación» -de acuerdo con la doctrina de Cossio- se limita a comprobar «la conformidad de la conducta con la norma», que se da «tanto si se cumplen las prestaciones como si se cumplen sus sanciones». En este sentido, «Juan debe pagar» mencionaría lo mismo que «Juan paga», al ser «verdadera» si y sólo si Juan paga.

\section{H. Conte y las «prescripciones necesariamente verdaderas»}

1. Según Amedeo Conte, las «proposiciones prescriptivas» serían «verdaderas» por ser «necesariamente verdaderas» (Primi argomenti per una critica del normativismo, Tipográfica del Libro, Pavia, 1968, p. 24).

A juicio de Conte, la «verdad» de una norma «consiste en su correspondencia con un status deóntico théticamente constituido», a través de su formulación «thética» («Paradigmática y sintagmática de la validez», en Amedeo G. Conte, Carlos Alarcón Cabrera, Deóntica de la validez, Tecnos, Madrid, 1995, p. 19).

2. Pero, aunque la norma que prohíbe A constituya el estatus deóntico del estar prohibido A, no podría atribuírsele la condición de ser «verdadera». En la norma la expresión «está prohibido», al no emplearse descriptivamente, carece de correlato objetivo. En rigor, mal podría hablarse entonces de «verdad como correspondencia con un status deóntico».

\section{Gardies y la estructura de las normas}

1. Jean-Louis Gardies -quien alaba a Kalinowski por «atribuir sin vacilar a los razonamientos normativos el valor lógico de verdad o de falsedad» 
(«Vingt années de recherches déontiques», Archives de Philosophie du Droit, 18, 1973, pp. 385-424)- plantea, por su parte, que «es menester analizar la norma» mediante la forma de un predicado con tres argumentos, uno de los cuales «designará la autoridad de la cual procede la norma, o, si se trata de una estricta obligación de derecho privado, el acreedor de esta obligación» («Le ròle des prédicats complétifs en logique déontique», Informatica $e$ Diritto, 9 (2), 1983, pp. 243-249).

A juicio de Gardies, «la estructura gramatical de la norma» «más general» es «aquella que hace aparecer, a la vez, después del predicado deóntico, el nombre del obligado, el nombre de quien obliga y la designación de la prestación» («Logique déontique et théorie générale des fonctions complétives», Logique et Analyse, 16, 1973, pp. 143-220).

2. Pero, en verdad, Gardies confunde un análisis de normas con análisis de enunciados o de situaciones deónticas (las que, como en Leibniz, pueden ser concebidas al margen de órdenes normativos). La autoridad de la cual procede una norma no se menciona en dicha norma.

El mismo Gardies manifiesta, en «Logique déontique et théorie générale des fonctions complétives» (p. 144), que en la literatura sobre la "estructura gramatical de la norma» habría encontrado «al menos seis maneras, bastante diferentes, de expresar que una acción es obligatoria», y considera, entre ellas, fórmulas de Anderson, García Máynez, Prior y von Wright, que no son normativas y se refieren, en cambio, a acciones o estados obligatorios.

3. Cabe señalar que el propio Gardies -que habla del «mundo presente en el cual la norma es obligatorio que $\mathrm{p}$ es verdadera» («La logique déontique et ses sémantiques posibles», Logique et Analyse, 82-83, 1978, pp. 185-203)- ha afirmado que las leyes estatales «no enuncian constataciones, sino lo que podemos llamar disposiciones» («La structure logique de la loi», Archives de Philosophie du Droit, 25, 1980, pp. 109-121).

\section{J. García Máynez y los «juicios normativos»}

1. En opinión de García Máynez, los «juicios normativos», «precisamente por referirse al orden del deber, difieren esencialmente de los que la doctrina tradicional toma en cuenta». Para él, mientras los «enunciativos» son verdaderos o falsos, «según que concuerden o no con las situaciones objetivas que pretenden describir», los «normativos» son «válidos» o «inválidos» («Lógica del juicio jurídico», Diánoia, 1, 1955, pp. 3-23).

Pero, según García Máynez, los asertos de los juristas también expresarían «juicios normativos», al emplear «tiene derecho a»o «está obligado a». Para el autor, las palabras «Quien descubra un tesoro en terreno ajeno tiene derecho a conservar para sí la mitad del tesoro y está obligado a entregar la 
otra mitad al dueño del predio», escritas en «un manual de derecho civil», no manifiestan un «enunciado», porque «no describen la conducta del sujeto que ha descubierto un tesoro ni, hipotéticamente, la de todos los que tengan esta suerte». La oración formularía «un juicio claramente normativo» (Positivismo jurídico, realismo sociológico y iusnaturalismo, UNAM, México, 1968, pp. 110-111).

2. «En el caso de los enunciados -plantea García Máynez- la verdad y la falsedad están condicionadas por la conveniencia o inconveniencia de la determinación predicada (relativamente al objeto-sujeto); en el caso de las normas, en cambio, la validez del acto imputativo depende de que los deberes o derechos que el precepto impone u otorga efectivamente correspondan a los sujetos sobre quienes la imputación recae» (Lógica del concepto jurídico, F.C.E., México, 1959, p. 24).

A juicio de García Máynez, sería menester, tratándose de las «leyes jurídicas», «investigar si tienen validez objetiva, o lo que es igual: poner en claro si constituyen la expresión de un auténtico deber ser» (El problema filosófico-jurídico de la validez del derecho, Imp. Mundial, México, 1935, pp. 37-38).

«Las normas -declara García Máynez- expresan precisamente la necesidad moral de que el destinatario realice un valor o serie de valores, cuya actualización depende del arbitrio y capacidades del obligado» (op. cit., p. 41).

3. «Objetivamente válido» es, pues, para García Máynez, el «precepto justo» (cf. su La definición del derecho, Stylo, México, 1948, p. 39). Según él, «si los juicios enunciativos son verdaderos cuando concuerdan con la realidad, la validez de los normativos tendrá que depender de su concordancia con lo valioso» (Lógica del juicio jurídico, EC.E., México, 1955, p. 77).

Pero García Máynez atribuye designata a las locuciones «tiene derecho a» y «está obligado a», correspondientes a los «juicios normativos». Él expresamente habla de los «correlatos de los conceptos de cópula prescriptiva y cópula atributiva» (Lógica del concepto jurídico, p. 183). Así, su concepción de las normas coincide, en lo fundamental, con la de Kalinowski.

\section{K. Normas y lógica sin verdad}

1. Hay, sin duda, sentencias -como las que suelen formularse en el seno de las comisiones legislativas, al considerar la justificación de un proyecto de ley- que enuncian, de acuerdo a ciertos criterios, que tales o cuales actos son «debidos», con independencia de órdenes normativos.

¿No podría entenderse -siendo los recursos lingüísticos muy limitados y siempre que por definición las normas no se distingan de los enunciados- que adquieren carácter normativo, al cumplirse determinadas formalidades, 
aquellas sentencias enunciativas que expresen la opinión de una mayoría de autoridades? Por cierto. Pero, ¿sabemos que existan ejemplares semejantes, para poder afirmar fundadamente al respecto: «Hay normas verdaderas o falsas»?

2. Al usarse «debe» diferentemente en distintas ocasiones -para mandar, significar estados normativamente obligatorios, o mencionar situaciones debidas con independencia de un orden normativo- se sientan, en verdad, las bases para distinguir entre el uso normativo y los enunciativos de «debe».

Se posibilita entonces considerar que: (a) hay sentencias, u ocurrencias de sentencias, que mandan, prohíben o autorizan, sin ser verdaderas o falsas; (b) tales expresiones -que emplean «debe» con los signos lógicos, regulan situaciones de conducta y son satisfechas o insatisfechas- no quedan, sin embargo, al margen de la lógica.

3. «Si se acepta que las normas carecen de valores de verdad -observa Eugenio Bulygin- no cabe duda de que una lógica de normas genuina sólo es posible si se amplía el concepto de lógica de tal manera que las conectivas proposicionales y los conceptos de implicación (consecuencia) lógica y de consistencia puedan ser definidos sin hacer referencia a la noción de verdad» («Lógica deóntica», en C. E. Alchourrón (ed.), Lógica, Trotta-Consejo Superior de Investigaciones Científicas, Madrid, 1995, p. 140).

«Una propuesta en tal sentido -añade Bulygin (p. 140)- fue formulada recientemente en Alchourrón-Martino, 1990. Estos autores proponen definir la noción de consecuencia lógica sobre la base del concepto abstracto de consecuencia (caracterizado por Tarski), que se usa como concepto primitivo y que no es ni sintáctico, ni semántico.»

4. El artículo al cual se refiere Bulygin es «Logic without truth» (Ratio Iuris 3 (1), 1990, pp. 46-67). Sus autores se basan en dos trabajos de Tarski, publicados por primera vez en 1930 y traducidos al inglés por J. H. Woodger: «On some fundamental concepts of metamathematics» $\mathrm{y}$ «Fundamental concepts of the methodology of the deductive sciences» (en A, Tarski, Logic, Semantics, Metamathematics. Papers from 1923 to 1938, Hackett, Indianapolis, 1990, 2a. ed.).

Tarski caracteriza por medio de una serie de axiomas el concepto de «consecuencia». Pero, como anotan W. A. Pogorzelski y S. J. Surma -en su recensión de la primera edición del libro de Tarski (The Journal of Symbolic Logic 34, 1969, pp. 99-106)esos axiomas «capturan sólo las propiedades más generales del concepto de prueba», que es sintáctico. Como el mismo Tarski expresa, las «consecuencias» "pueden ser obtenidas mediante ciertas operaciones llamadas reglas de inferencia» (On Some Fundamental Concepts of Metamathematics, p. 30). 
Con razón, John Etchemendy ha podido afirmar que en dichos trabajos Tarski «asume una visión puramente sintáctica», conforme con «el enfoque sintáctico de la relación de consecuencia que prevalecía entonces» («Tarski on Truth and Logical Consequence», The Journal of Symbolic Logic 53, 1988, pp. 51-79).

5. La propuesta de Alchourrón y Martino adopta, así, una concepción sintáctica.

Como admiten los autores, determinan el uso de conectivas y operadores mediante «reglas de naturaleza sintáctica» (op. cit., p. 60). Según reconoce Alchourrón, «es apropiado decir que en un enfoque abstracto los axiomas referidos a los signos lógicos determinan su significado sintáctico» («Concepciones de la lógica», en Lógica, cit., p. 41).

6. Como bien dice Alchourrón, si de las leyes generales promulgadas por el legislador «no se pudiera concluir deductivamente» la totalidad de las normas que «refieren el contenido de la ley general a cada uno de los súbditos», entonces las leyes generales «se convertirían en meros juguetes vistosos sin la significatividad normativa con que incuestionablemente son entendidas en la vida social» (op. cit., pp. 35-36).

Pero, si no se pudiese interpretar sus expresiones y determinar sus relaciones con la realidad y con sus usuarios, las leyes también serían «meros juguetes vistosos sin la significatividad normativa con que incuestionablemente son entendidas en la vida social».

7. Principios básicos para precisar el significado (no-sintáctico) de las expresiones normativas son, a nuestro juicio, los siguientes:

(1) Son lógicamente equivalentes las normas con componentes enunciativos lógicamente equivalentes;

(2) Una norma de la forma «Debe ser (p y q)» es lógicamente equivalente con la conjunción de las correspondientes normas de las formas «Dp»y «Dq»;

(3) La norma que ordena (que) $p$ es lógicamente incompatible con la que ordena no-p;

(4) Las conectivas sentenciales y sus definiciones son plenamente utilizables en fórmulas normativas;

(5) Una norma y su negación (externa) son contradictorias;

(6) Las fórmulas que, de acuerdo con las reglas de formación, sean mixtas -como los condicionales con antecedente enunciativo y consecuente normativo- son normas;

(7) Los valores de las normas son «validez»e «invalidez»;

(8) Una conjunción de normas es válida si y sólo si sus miembros son válidos; 
(9) El valor de las normas mixtas se determina considerando los valores de verdad o falsedad como si fuesen de validez o invalidez;

(10) Una norma es válida si y sólo si el correspondiente enunciado normativo es verdadero. 